\title{
DIÁLOGOS INSTITUCIONAIS FRENTE À PRETENSÃO DE ÚLTIMA PALAVRA DO STF: CONTRIBUIÇÕES CANADENSES PARA O MODELO BRASILEIRO DE INTERPRETAÇÃO CONSTITUCIONAL
}

\author{
Camila Salgueiro da Purificação Marques ${ }^{1}$ \\ Claudia Maria Barbosa ${ }^{2}$
}

\begin{abstract}
RESUMO: Verifica-se em democracias contemporâneas assentadas na supremacia da norma constitucional o fortalecimento do processo de interpretação da Constituição, comumente atribuído às Cortes Constitucionais. O Brasil segue essa tendência, pois definiu ser o STF guardião da Constituição. Os pressupostos de Peter Haberle expõem o processo interpretativo como um ato de constituição do significado da norma constitucional, sendo discutível a competência das Cortes Constitucionais para exercer com prioridade sobre os demais órgãos esse papel. O artigo refuta os argumentos que favoreceriam a última palavra e, apresenta a proposta dos diálogos constitucionais canadenses como uma opção mais democrática para a realização da Constituição.
\end{abstract}

PALAVRAS-CHAVE: Judiciário, Controle de constitucionalidade, Diálogos institucionais, Participação Popular.

\section{INSTITUTIONAL DIALOGUES REGARDING THE BRASILIAN SUPREME COURT ASSUMPTION TO STABLISH THE LAST WORD: CANADIAN CONTRIBUTIONS TO THE BRAZILIAN MODEL OF CONSTITUTIONAL INTERPRETATION}

\begin{abstract}
It is verified in contemporary democracies based on the supremacy of the constitutional norm the strengthening of the process of interpretation of the Constitution, commonly attributed to the Constitutional Courts. Brazil follows this trend, since it defined the STF as the guardian of the Constitution. Peter Haberle's assumptions expose the interpretative process as an act of constitution of the meaning of the constitutional norm, therefore, it is debatable the competence of the Constitutional Courts to exercise this role with priority over the other branches. The article refutes the arguments that would favor the last word and presents the proposal of the Canadian constitutional dialogues as a more democratic option for the realization of the Constitution.
\end{abstract}

KEYWORDS: Judiciary, Judicial Review, Institutional Dialogues, Public Participation.

\footnotetext{
${ }^{1}$ Professora. Doutoranda em Direito na Pontifícia Universidade Católica do Paraná - Bolsista CAPES/Fundação Araucária. Mestre em Direito pela Pontifícia Universidade Católica de São Paulo. Barachel em Direito pela Universidade Estadual de Ponta Grossa. camila_purificacao@yahoo.com.br

${ }^{2}$ Professora titular na Pontifícia Universidade Católica do Paraná. Pós-Doutora na York University, Toronto, Canadá. Doutora, mestre e graduada pela Universidade Federal de Santa Catarina. claudia.mr.barbosa@gmail.com
} 


\section{Introdução}

O presente artigo objetiva analisar as implicações antidemocráticas do controle de constitucionalidade das leis pelo Judiciário e os possíveis diálogos institucionais entre os três Poderes, realizando apontamentos sobre o cenário brasileiro e canadense, especialmente sobre este último, de modo a impulsionar reflexões sobre o sistema brasileiro.

O que se justifica diante do forte controle de constitucionalidade existente no Brasil, principalmente no tocante ao controle das políticas públicas, realizado pelo Supremo Tribunal Federal - STF, assim como pela pretensão de que este tenha a última palavra sobre a interpretação da Constituição de 1988.

Dessa forma, priorizando o método de abordagem lógico-dedutivo e a documentação indireta, o estudo utiliza-se da pesquisa bibliográfica, documental, legislativa e jurisprudencial para analisar os principais argumentos contrários à um forte controle de constitucionalidade por parte do Judiciário, mormente no tocante à desarrazoada pretensão do Judiciário brasileiro de ter a última palavra sobre a interpretação da Constituição. Para, posteriormente, especificar a temática analisando os possíveis diálogos entre os Poderes, especialmente entre o Judiciário e o Legislativo, com foco na comparação entre o Brasil e o Canadá.

Isto é, tem-se por hipótese, confirmada no decorrer da pesquisa, a necessidade de um maior diálogo entre os Poderes na tomada de decisões relevantes e que dizem respeito às questões políticas, a exemplo dos diálogos constitucionais canadenses, como uma opção mais democrática e legítima para a realização da Constituição.

\section{Implicações antidemocráticas do controle de constitucionalidade das leis pelo Judiciário}

Por meio do trabalho "El Federalista" n. 78, Alexander Hamilton defendeu a possibilidade de os juízes impugnarem a validade das leis, negando as implicações antidemocráticas de tal controle. Ele argumentava que a decisão de anular uma lei reafirmava o peso da vontade popular, pois ratifica a soberania da Constituição, que é o documento que melhor expressa a vontade do povo, devendo prevalecer as normas fundamentais e não aquelas que são contrárias à Constituição. (GARGARELLA, 1997, p. 56).

Inclusive, tal argumentação de Alexander Hamilton se tornou célebre no caso Marbury x Madison, julgado pelo juiz Marshall, assim como tal controle de constitucionalidade foi reforçado com Kelsen. Segundo Virgílio Afonso da Silva, "se, com Marshall, é colocada em prática a ideia de controle de constitucionalidade, o projeto de Kelsen dá vida à ideia de um tribunal especificamente encarregado desse controle e monopolizador das decisões de 
inconstitucionalidade”. A relevância dos papéis de Kelsen e Marshall se dá pela importância da fundamentação utilizada para defender o controle de constitucionalidade, que é reproduzida até hoje. (2009, p. 200-201).

Contudo, há razões significativas para contrapor o argumento de Alexander Hamilton, principalmente quando se trata de um forte controle de constitucionalidade, a seguir elencadas.

Em primeiro lugar, com fundamento na obra de Roberto Gargarella, refuta-se o argumento histórico no sentido de que no momento da elaboração da Constituição dos Estados Unidos e de outros países, parte do povo foi excluído, pois escravos, mulheres e pobres, por exemplo, não participaram direta ou indiretamente do processo constitucional. É como ressalta o autor, o argumento histórico não contribui suficientemente para o seu propósito, tendo em vista que poderia haver um processo constitucional no qual todos os setores fossem bem representados. (GARGARELLA, 1997, p. 57)

$\mathrm{Na}$ sequência, destaca-se o argumento intertemporal, que foi desenvolvido especialmente por Bruce Ackerman, nos Estados Unidos. Nesse sentido, afirma que se valora especialmente esse "primeiro momento constitucional", por que não se pode pensar, com o passar do tempo, a encontrar um consenso popular profundo sobre a vontade atual dos cidadãos? Este sim é um argumento suficiente para combater a argumentação "HamiltonMarshall”. Contudo, Ackerman sugere manter o controle constitucional, mas estendido também a novos acordos amplos e profundos dos cidadãos. Por isso, ainda é necessário um terceiro argumento. (GARGARELLA, 1997, p. 57-58)

Por fim, o argumento sobre a interpretação. Isto é, quando o defensor do controle de constitucionalidade se refere à tarefa judicial, ele o faz pressupondo o caráter nada problemático da interpretação, considerando a tarefa dos juízes frente a Constituição como uma tarefa automática. Todavia, os juízes realizam muito mais do que uma leitura da Constituição, sendo que, muitas vezes, incorporam ao texto soluções normativas que nele não estavam explícitas. Dessa forma, ao decidir questões como esta e outras fundamentais, acabam por ocupar o lugar dos legisladores. E, ainda, pode ocorrer que a Constituição faça referência a uma determinada solução normativa, mas frente à um caso concreto, não se saiba qual interpretação realizar. E com o poder de dar a "interpretação adequada" a tais situações, passam a concentrar em suas mãos um enorme poder de decisão. Nesse contexto, foi Alexander Bickel, que contribuiu com o renascimento da crítica que ele denominou de "caráter contramajoritário" do poder judicial. (GARGARELLA, 1997, p. 59) 
Assim, não há que se falar na crise dos órgãos políticos e que as funções dos juízes os levariam a estar em permanente contato com o cidadão comum, pois se há uma "crise" dos órgãos políticos, deve-se "aperfeiçoar os mecanismos majoritários” e não se desfazer deles. Até porque o Judiciário também é afetado pelos problemas dos outros dois poderes, sendo que as decisões dos juízes também podem ser motivadas por interesses próprios, assim como não se encontram livres de pressões externas, mormente em países nos quais o Poder Judiciário não é independente em relação aos órgãos políticos. Além disso, o contato dos juízes com os cidadãos no exercício da função é informal e ocasional. Por isso, deve-se verificar como esses juízes são eleitos e se o são a partir de um processo majoritário, assim como se as suas decisões são ou não sujeitas a periódicos controles dos cidadãos. (GARGARELLA, 1997, p. 62-63). Tampouco o Judiciário garante a proteção das minorias, pois os juízes não representam a maioria numericamente falando, assim como não representam ou possuem uma conexão especial com a infinita diversidade de minorias que existem na sociedade. (GARGARELLA, 1997, p. 63-65)

E ainda não se pode dizer que o Judiciário age de modo mais racional e imparcial do que o Legislativo e o Executivo. Isso porque, como defende Roberto Gargarella, esta análise está tomada de um "elitismo epistemológico". Inclusive, a ausência de um processo democrático de eleição dos juízes pode implicar que estes elejam um modo de resolução de conflito que desconheça algum ponto de vista relevante. E é justamente na decisão de questões constitucionais básicas que se requer um amplo processo de consulta e discussão. E em um diálogo entre os juízes e os cidadãos somente os primeiros teriam o direito de dizer a última palavra, ao passo que os cidadãos só poderiam esperar que os juízes de bem levassem em conta os seus pontos de vista. (GARGARELLA, 1997, p. 65-67)

No mesmo sentido é o entendimento de Juliano Zaiden Benvindo:

Normalmente, as premissas construídas em favor de um reforço do papel do Judiciário se dão por uma associação direta com perspectivas teóricas e pragmáticas que lhe dão essa configuração. E qualquer tentativa de questionar tais premissas é lançada ao campo das heresias. Com esse propósito, encontram-se justificações que vão, por exemplo, buscar suas origens nas bases do constitucionalismo norte-americano, que deram ensejo à construção do judicial review, como se visualiza na clássica, embora polêmica, decisão de 1803 de sua Suprema Corte, em Marbury vs. Madison, a qual acabou ganhando contornos doutrinários bem mais ampliativos do que os próprios termos do Justice John Marshall, relator do caso. Mas podem ir além, tentando encontrar nos próprios discursos dos federalistas e na estrutura da noção de checks and balances a base desse argumento, apresentando a corte constitucional como um elemento importante no equilíbrio institucional, sobretudo no âmbito de defesa de minorias, muito embora a noção de judicial review aqui se apresente bastante diversa de uma noção de supremacia. (BENVINDO, 2014, p. 83-84) 
O problema central, segundo o mesmo autor, é que todos esses argumentos, apesar de soarem convincentes, somente ganham seu devido valor se forem afirmados por uma prática que os justifique. Desse modo, "querer se afirmar o detentor da "última palavra" não é tarefa que pode se resumir a uma retórica vazia", sob pena de o discurso perder em legitimidade. Por isso, concorda-se com o autor pela impossibilidade de se ter a "última palavra" em uma sociedade democrática complexa e que preza pela cidadania. "Ter a tão desejada "última palavra" é custoso, porquanto lança, para um único órgão, a defesa institucional final de todo um processo democrático, de todo um diálogo que quer se manter aberto, em que a democracia e o constitucionalismo, como paradoxos necessários, se constroem e se aperfeiçoam”. No Brasil, inclusive, embora o Supremo Tribunal Federal se utilize desse argumento, por outro lado, deixa a desejar na justificação de tal premissa. (BENVINDO, 2014, p. 83-84)

Inclusive, a questão da necessidade de um guardião, encontra lugar em várias dicotomias, entre elas procedimentalismo $x$ substancialismo, visão republicana $x$ visão liberal, democracia $x$ direitos individuais, todas ligadas àquela estabelecida por Benjamin Constant $\mathrm{e}$ retomada por Isaiah Berlin entre as liberdades dos antigos e a liberdade dos modernos, porque correspondente à contraposição entre participação política e a garantia de uma esfera inviolável de liberdades e direitos. (SILVA, 2009, p. 202-203). Virgílio Afonso da Silva resume o debate analisando a distinção entre o fórum dos princípios (Dworkin) e a maximização da participação popular (WALDRON, 2006 ${ }^{3}$ ).

Resumidamente, a concepção de Dworkin é a de que uma democracia constitucional tem duas dimensões: (i) política (discussão popular sobre interesses coletivos) e (ii) dos princípios (proteção dos direitos individuais). O locus por excelência de discussão deste último é o Judiciário, onde os princípios servem de trunfo contra decisões políticas. O controle se justificaria (e a sua legitimidade) para proteger os direitos individuais das decisões das maiorias. Já para Waldron, usar os direitos individuais como trunfo ignoraria o "desacordo moral existente em sociedades plurais", o qual diz que as pessoas têm concepções diferentes acerca de seus direitos mais básicos. Assim, não seria a elite judiciária a mais legitimada a decidir sobre esses direitos fundamentais, mas os cidadãos, em condição de igualdade. Segundo Waldron, o direito à participação é o "direito dos direitos". Para o Virgílio Afonso da Silva, esses debates todos pecam pelo maniqueísmo entre "todo poder aos juízes" e "todo poder ao legislador" ${ }^{\prime 4}$ (2009, p. 203-204)

\footnotetext{
${ }^{3}$ Verificar: WALDRON, 2006.

${ }^{4}$ Ainda, segundo o autor, é necessário analisar um debate paralelo ao da legitimidade do controle, para discutir sobre o órgão por ele responsável. Aqui a dicotomia é representada por Kelsen e Schmitt ${ }^{4}$, sendo que o primeiro
} 
Ademais, Juliano Zaiden Benvindo questiona por que falamos tanto em diálogo institucional? Será que harmonia e diálogo institucional não escondem o que ocorre na prática, nos jogos inerentemente políticos - e, pois, marcados pelo desacordo em grande medida - que ocorrem entre os Poderes e dentro de cada um deles? Assim, por exemplo, é altamente falacioso acreditar que o Judiciário é meramente um Poder técnico e, desse modo, alheio à política, aos jogos de poder, como se o âmbito do Direito discutido pelos tribunais fosse o local da sabedoria, da dignidade interpretativa, da racionalidade, enquanto o da política seria um mundo sombrio, imprevisível, caótico e irracional. (BENVINDO, 2014, p. 73)

Assim, pergunta: como imaginar o arranjo institucional entre os diferentes Poderes (seja ele interpretado como uma contínua competição e um forte desacordo, seja como um diálogo - embora aqui se trate de um diálogo ciente das disputas por poder), diante dos desafios que se lançam em um contexto de consolidação de uma democracia constitucional como a brasileira? É preciso imaginar como tais competições entre os Poderes, já mencionadas por Madison, não se revelem, em último grau, mecanismos usurpadores do poder. Surge, dessa instigação, o alerta de como manter a cidadania, que é condição da democracia, diante de um “querer mais poder" que se dá nessa visível competição entre os Poderes. (BENVINDO, 2014, p. 74)

O conflito, portanto, não se dá apenas no nível da ação; ele atinge, sobretudo, o próprio discurso. Aqui se apresenta toda uma necessidade de desmistificar o Judiciário e resgatar uma legitimidade perdida do Parlamento. Juliano Zaiden Benvindo também se apoia em Waldron para afirmar que as “cortes são também um fórum para tomar decisões sociais em um contexto de desacordo, mas, embora tenham muitas vantagens, não são necessariamente as mais representativas ou as mais respeitadoras das vozes divergentes na comunidade”. (BENVINDO, 2014, p. 78 e 79)

Em sintonia com o que foi até agora apresentado, a história complementa significativamente a percepção de que, no âmbito de uma disputa política constante entre os Poderes - e, não, harmonia, como já se afirmou -, é falacioso sustentar, sem maior análise crítica, que o Judiciário tem a primazia da "última palavra" no Direito, até mesmo no âmbito dos desacordos políticos sobre direitos. A tese a ser defendida é que a própria construção argumentativa de algum Poder "detentor da última palavra" é, por si só, uma afirmação que aparece como discurso por mais poder. Até porque não existe, em uma democracia constitucional, que prima pela cidadania, um órgão que possa arvorar-se o detentor da última palavra. Entretanto, o processo histórico

coloca esse poder nas mãos de um tribunal constitucional e o segundo nas mãos do Presidente da República. Para ele, o debate é mais simbólico que real, pois os autores tratavam de conceitos distintos de constituição e de ameaças também distintas, seria o "embate entre o controle de constitucionalidade do dia-a-dia contra a guarda da constituição contra ameaças ao regime político”. (SILVA, 2009, p.205-206) 
brasileiro, nesses vinte e cinco anos de constitucionalismo, consubstanciou essa premissa. O caminho agora é desconstruí-la ”. (BENVINDO, 2014, p. 80)

Inclusive, sob outro viés, Ran Hirschl (2007), afirma que a judicialização da política é uma função de escolhas concretas, interesses ou considerações estratégicas de atores políticos autointeressados e que muito desse processo decorre da premissa de que delegar a autoridade de fazer política para as Cortes pode ser um meio eficiente de transferir responsabilidade e, portanto, reduzir seus riscos (dos políticos) e do aparato institucional em que eles operam. Desse modo, o deslocamento da esfera política para as cortes constitucionais das decisões sobre questões não meramente políticas, mas sim questões cruciais e elementares para a definição da própria política de uma nação costuma ocorrer em sociedades democráticas que enfrentam graves clivagens étnicas, linguísticas ou religiosas (como ocorreu nos casos do Canadá, em relação ao Quebec; em Israel, em relação à definição de quem seria "judeu”; e na África do Sul, em que a Corte recusou um texto de reforma constitucional). Em todos esses casos, segundo Hischrl, as cortes decidiram em consonância com os interesses daqueles que lhes empoderaram. (HIRSCHL, 2007, p. 172-173)

\section{O controle de constitucionalidade das leis e os possíveis diálogos constitucionais: Brasil e Canadá}

No tocante à tomada de decisão do Judiciário e ao controle de constitucionalidade, ressalta-se que existem duas espécies de deliberação: a interna e a externa. A deliberação interna envolve a troca de razões e argumentos dentro de um grupo para que ele chegue a uma decisão (entre os juízes), já a deliberação externa envolve o esforço para convencer atores externos aos grupos (diálogo entre juízes e o mundo externo). Assim, no modelo europeu, a deliberação é interna, no norte-americano, externa. Isso implica que no primeiro caso haja um longo debate entre os juízes e convencimento através do diálogo, gerando uma decisão "única, institucional, clara, objetiva e de consenso", enquanto no modelo norte-americano "os juízes praticamente não interagem entre si e não deliberam no sentido estrito da palavra", sendo que "é possível indagar, se de fato os juízes da Suprema Corte americana têm como objetivo primordial persuadir seus colegas acerca da correção de suas opiniões”, de modo que, para Virgílio Afonso da Silva "sua plateia é externa: é o Congresso, a Casa Branca, as faculdades de direito, são os jornalistas". (SILVA, 2009, p. 210-211).

Para o autor, uma democracia precisa de ambos os tipos de deliberação. É preciso que o tribunal fale de maneira clara, objetiva e única - deliberação interna - e, também, em uma 
diferente forma de exercício da deliberação externa, a partir de um diálogo entre tribunal, sociedade civil e poderes políticos (diálogo entre poderes, diálogo constitucional), sem necessária fragmentação da deliberação ou desagregação argumentativa. A realização desse diálogo externo exige a análise de formas alternativas de controle judicial de constitucionalidade, portanto. (SILVA, 2009, p. 210-212).

Inclusive, o debate controle forte x controle fraco orbita a facilidade ou dificuldade de o Legislativo rediscutir as decisões tomadas no âmbito do controle judicial de constitucionalidade, podendo superá-las ("superação legislativa" ou legislative override). (SILVA, 2009, p. 211-212). Nesse caso, a maioria dos países europeus e os EUA podem ser considerados modelos fortes, porque a única possibilidade de superação da decisão do tribunal é por meio de emenda constitucional. Enquanto isso, os modelos canadense e inglês seriam considerados fracos, no primeiro caso porque o legislador pode re-promulgar a lei declarada inconstitucional e no caso inglês porque segundo o Human Rights Act, de 1998, que instituiu o controle, este não vincula totalmente o legislador, sendo decisões de incompatibilidade, não de invalidade. (SILVA, 2009, p. 212-213)

Sobre o Canadá especificamente, destaca-se que no ensejo de críticas à atuação da Suprema Corte norte-americana, começam a surgir novas propostas de conformação do instituto do judicial review. O Canadá possui tradição jurídica e política ligada à Inglaterra, e, assim, convivia com o princípio da supremacia do Parlamento. Todavia, por ocasião das discussões para a implementação de sua Carta de Direitos de 1982, acabou optando por fazer a previsão de um tipo de controle judicial de constitucionalidade que institucionaliza o diálogo institucional. E cumpre salientar as notas características da ordem jurídica daquele país: sistema do Common Law, somado a uma tradição de soberania do Parlamento de molde inglês, com recente introdução do judicial review, mitigado, porém, por uma cláusula que permite ao Parlamento a manutenção de legislação em vigor, ainda que contra decisão judicial expressa em sentido contrário (cláusula notwithstanding). (VICTOR, 2015, p.187).

Esse novo sistema de controle judicial de constitucionalidade, sobretudo em virtude da adoção da chamada cláusula notwithstanding, foi considerado por Hogg e Bushell como caracterizador de um modelo dialógico de judicial review, em razão de a referida cláusula permitir essa resposta legislativa à decisão da Suprema Corte. Para os autores, o novo modelo ajudaria a dissolver a dificuldade contramajoritária. Isto é, diante dessas objeções ao papel da Cortes, em especial da Suprema Corte como detentora da última palavra sobre o significado da 
Constituição, surge, com naturalidade, a ideia de diálogo institucional. (VICTOR, 2015, p.187188).

Carlos Alexandre de Azevedo Campos também ressalta que o desenvolvimento do ativismo judicial no Canadá está relacionado, principalmente, às destacadas transformações institucionais operadas pela Canadian Charter of Rights and Freedom, a "Charter”, de 1982, que é uma Carta de direitos dotada de status constitucional e de forte proteção judicial. Esta "substituiu o modelo anterior, a Canadin Bill of Rights (CBOR) de 1960, que tinha apenas força de lei ordinária, modificável em qualquer tempo pelo Parlamento". Com a Carta anterior a Suprema Corte do Canadá pouco se ocupava de questões constitucionais e exerceu a judicial review em uma única oportunidade. Mas, com o novo modelo, a Corte passou a ter especial interesse pelas questões constitucionais e na interpretação das leis de ampla aplicabilidade. Desse modo, a Corte afastou leis que restringiram o aborto, permitiram a discriminação por orientação sexual, limitaram a condição de cônjuges a casais heterossexuais, reduziram o acesso ao seguro-saúde, violaram direitos eleitorais de prisioneiros, por exemplo. ${ }^{5}$ (CAMPOS, 2014, p. 137-138). E sobre este ativismo judicial no Canadá ${ }^{6}$, destacam-se os mecanismos de legitimação das decisões da Corte:

(...) os canadenses, diferentes dos norte-americanos, não devem temer o ativismo judicial ou a supremacia judicial haja vista a estrutura da Charter permitir que mesmo as decisões mais ativistas sejam revistas em meio a um diálogo democrático entre cortes e poderes políticos - mecanismos institucionais da Charter fazem com que a Suprema Corte não tenha a palavra final sobre a constitucionalidade das leis, sendo suas decisões, na realidade, uma etapa importante, mas não a única nem mesmo a definitiva, do processo de interpretação constitucional e infraconstitucional que envolve reações e respostas pelos poderes Executivo e Legislativo e pela própria sociedade. - grifo do autor. - g. n. (CAMPOS, 2014, p. 139) ${ }^{7}$

Tais diálogos ocorrem com base na Section 1 da Charter, que faz referência à possibilidade de imposição de limites apenas razoáveis aos direitos garantidos pela Charter,

\footnotetext{
${ }^{5}$ Além da nova Charter, outros fatores contribuíram para a expansão do ativismo judicial da Suprema Corte canadense: “(...). A disposição dos diferentes atores políticos em transferir para a Suprema Corte a autoridade decisória sobre questões fundamentais, as mudanças legislativas que ampliaram a discricionariedade da Corte na determinação de sua agenda, a estrutura da judicial review que mistura o controle difuso e concreto com o controle abstrato na Suprema Corte e a sua própria jurisprudência, que ampliou o campo de legitimados e de terceiros intervenientes que lhe podem deduzir pretensões, são outros fatores importantes que, em conjunto, têm conduzido a um ativismo judicial, segundo Hischl, em nível de igualdade e, em alguns aspectos, até superior ao experimentado pelos Estados Unidos na era pós-Brown." (CAMPOS, 2014, p. 138-139)

${ }^{6}$ Há autores contrários ao ativismo judicial: CAMERON, 2009; LEISHMAN, 2009.

${ }^{7}$ Nesse sentido: HOGG, BUSHELL, 1997, p. 81.
} 
assim como a Section 33, que permite a supressão legislativa da decisão ${ }^{8}$. Importa notar que a

Section 1 é o grande veículo para as regulações e intercâmbios que regularmente ocorrem entre

Cortes e legisladores no Canadá ${ }^{2}$. Por meio da Section 1, legislador e Suprema Corte podem

entrar em diálogo sobre quais medidas razoáveis as leis podem adotar para restringir direitos da

Charter:

Em R. v. Oakes, a Suprema Corte definiu os parâmetros que o legislador deve observar para restringir, de forma razoável, direitos e liberdades: (1) a lei restritiva deve perseguir um objetivo importante; (2) a restrição deve ser racionalmente conectada com esse objetivo; (3) a lei deve restringir o direito não mais que o necessário para alcançar o objetivo; (4) a restrição não deve ter um efeito desproporcionalmente severo para os seus destinatários. Tratase do teste da proporcionalidade. Uma vez que a lei, a juízo da Suprema Corte, persiga um objetivo relevante, sem que, para tanto, restrinja o direito mais que o necessário e de forma desproporcional, então ela deverá ser declarada constitucional.

Na hipótese de uma lei não satisfazer os parâmetros da section 1, a Corte declarará a lei inconstitucional e poderá dar início ao processo de diálogo. Segundo Hogg e Bushell, em declarar a inconstitucionalidade da lei com base nos parâmetros de razoabilidade, a Suprema Corte "explicará porque o standard da section 1 não foi satisfeito" e, assim, indicará "a alternativa legal menos restritiva que teria satisfeito a section 1". O legislador poderá então, utilizando a formulação da Corte, realizar uma "segunda tentativa". Na prática, o diálogo pela section 1 pode se realizar com (1) a declaração de inconstitucionalidade pela Suprema Corte e a indicação das condições de restrição razoável que não foram justificadas; (2) a instituição de nova disciplina legal pelo legislador, visando, substancialmente, alcançar os mesmos propósitos da lei declarada inválida, mas levando em conta a análise pela Corte sobre os "meios menos restritivos" que satisfariam os parâmetros da section 1 da Charter. É possível, ainda, um terceiro round, (3) com a Corte revisando a constitucionalidade da resposta legislativa, sendo deferente ao legislador ou recusando novamente a lei.

\footnotetext{
${ }^{8}$ A Section 33 funciona do seguinte modo: "O artigo 33 da Chartes estabelece a possibilidade do uso pelo legislador, federal ou das províncias, da chamada notwithstanding clause ("cláusula não obstante"). O Parlamento pode inserir essa cláusula em uma lei e, com isso, obter o efeito de impedir que a Suprema Corte declare essa lei inconstitucional não obstante ter concluído efetivamente pela violação aos direitos fundamentais dos artigos $2^{\circ} \mathrm{e}$ $7^{\circ}$ ao $15 \mathrm{da}$ Charter. Este dispositivo também permite ao legislador republicar lei original declarada inconstitucional, afastando, dessa feita, a mácula de inconstitucionalidade (legislative override) e neutralizando a interferência da Suprema Corte. Trata-se, como disseram os autores, do "meio mais óbvio e direto de superação de uma decisão judicial que anule certa lei por violação aos direitos da Charter”. A vigência dessa cláusula é limitada ao prazo, renovável de cinco anos.

Todavia, o uso do notwithstanding clause tem sido escasso. Na prática, ela "tem se tornado desimportante por causa do desenvolvimento de um clima político de resistência ao seu uso". Os custos políticos são altos tendo em vista a impopularidade desse tipo de enfrentamento. Entre as dez províncias e três territórios do Canadá, apenas Alberta, Saskatchwan e Yukon utilizaram a cláusula ao menos em uma oportunidade, enquanto Québec fez uso mais frequente do mecanismo. Como forma de protesto à própria promulgação da Charter, o governo separatista de Québec introduziu a notwithstading clause em todas as suas leis. A Suprema Corte deferiu ao legislador da província e declinou em revisar a constitucionalidade dessas leis. Destaque a resposta legislativa à paradigmática decisão que considerou inconstitucional lei de Quebec que havia proibido o uso de outra língua além do Francês em letreiros comerciais. Porém, tendo expirado, em 1993, o prazo de cinco anos da cláusula, esta não foi renovada e o legislador promulgou nova lei, menos restritiva, permitindo o uso de outras línguas em qualquer hipótese, desde que o Francês também fosse utilizado e de forma predominante". (CAMPOS, 2014, p. 140-141)

${ }^{9}$ Nesse sentido: ROACH.
} 
Com o diálogo operando dessa forma, o processo democrático é influenciado pela Suprema Corte, mas não é por ela anulado. Assim, a ideia principal dos autores por trás da defesa dessa prática, é a afirmação que o diálogo entre a Suprema Corte e o Legislativo, marcado pelas respostas legislativas às decisões da Corte, caracteriza, sobre o ponto de vista descritivo, que o Canadá possui uma forma mais fraca de judicial review em relação aos Estados Unidos e, sob o ponto de vista normativo, que isso minimiza o discurso de ilegitimidade democrática do ativismo judicial em torno da Charter. Em um primeiro momento, podemos ter decisões ativistas, em um segundo, respostas legislativas a essas decisões de forma que o processo legislativo resulte de uma dinâmica institucional bilateral, dialógica e não unilateral. - g. n. (CAMPOS, 2014, p. 142-143) ${ }^{10}$

E é interessante anotar que, no sistema canadense, o artigo 53 da Lei sobre a Suprema Corte a obriga a se pronunciar sobre toda questão de direito ou de fato que lhe for submetida pelo governo federal, para que o legislador saiba previamente a posição da Corte em questões que envolvam matéria constitucional. “Apesar desta disposição legal, a Corte já decidiu que sua resposta é necessária (e obrigatória) apenas quando não se tratar de uma questão de natureza meramente política". Inclusive, por meio do artigo 52 do "A to constitucional”, o cidadão pode ter acesso à Corte para questionar a constitucionalidade de uma determinada lei que contém disposições contrárias à Carta Canadense de Direitos e Liberdades”. (BARBOSA, 2002, p. 132133)

Além disso, todas as normas e atos administrativos, assim como as decisões dos tribunais administrativos, são submetidas ao controle de constitucionalidade. Porém, as leis votadas pelo Parlamento são as espécies normativas que o Poder Judiciário tem mais receio de declarar contrárias à Constituição, tendo em vista que expressam, ainda que em tese, a vontade coletiva (legislatura representativa). Assim, existem diversos mecanismos adotados de forma expressa ou implícita pelas cortes que visam assegurar um necessário equilíbrio entre os poderes de estado e, por outro lado, "garantir a independência necessária ao Poder Judiciário quando da apreciação de disposições normativas que lhe são submetidas". No Canadá, inclusive, diferentemente do Brasil, há outras diversas regras, por meio das quais o Poder Judiciário procura garantir a aplicação da Constituição sem, no entanto, interferir desnecessariamente nas atividades dos outros dois poderes, buscando uma decisão que leve em conta a intenção originária do legislador, a interpretação conciliatória, a interpretação conforme, etc. (BARBOSA, 2002, p. 141 e 143-144).

De qualquer modo, há que destacar que os modelos canadense e inglês permitem algum controle ao juiz, sob pena de equívoco, por várias razões: (i) ignora-se o valor do debate,

${ }^{10}$ Nesse sentido: STITT, 2003. 
porque a decisão do tribunal cria um ônus deliberativo para o legislador e também porque desacelera o debate político (caso de decisões legislativas tomadas em momentos de crises circunstanciais); (ii) ignora-se a experiência concreta (no Canadá, estudos demonstram que o legislador quase nunca se utiliza da superação legislativa), uma vez que a decisão do tribunal cria um ônus político que os legisladores poucas vezes querem enfrentar; (iii) compreende o controle judicial apenas no sentido jurídico-formal, ou seja, processual, e não como um diálogo que é, e como tal, que não tem fim, está sempre aberto a novos argumentos. (SILVA, 2009, p. 213-214).

Por outro lado, o modelo brasileiro surge claramente inspirado pelo modelo norteamericano, ou seja, de forte controle judicial. O sistema criado com a proclamação da República era claramente difuso e posterior à lei. Havia uma hesitação em exercer o controle, em virtude da separação dos poderes, e a consolidação do seu uso se deveu a dois atores: Rui Barbosa, enquanto advogado e orador, e Pedro Lessa, enquanto ministro do Supremo Tribunal Federal. E a partir de 1934 o Brasil passou a sofrer um processo de concentração do controle, com a primeira forma de previsão da ADI (Ação direta de inconstitucionalidade). Mas, "o caminho para a concentração não significou um caminho para o modelo europeu", afirmar isto seria permanecer preso aos binômios prévio-posterior e difuso-concentrado. (SILVA, 2009, p. 214216)

Inclusive, para o Virgílio Afonso da Silva, o modelo brasileiro não pode ser considerado como modelo de deliberação interna, devido a três fatores: (i) quase total ausência de trocas de argumentos entre os ministros; (ii) inexistência de unidade institucional e decisória; (iii) carência de decisões claras, objetivas e que veiculem a opinião do tribunal. O modelo brasileiro poderia ser considerado ultra forte, porque além de reunir as características norteamericanas, possui as cláusulas pétreas. (2009, p. 217-218)

Para o autor, "é preciso tornar o STF uma instituição que tenha voz própria, que não seja a soma de 11 vozes dissociadas", isso porque a unidade institucional é essencial para o diálogo entre instituições e porque a vinculação de suas decisões depende, em certa medida, da aludida unidade ${ }^{11}$. Para fomentar essa mudança no âmbito da deliberação, segundo o autor,

\footnotetext{
11 No mesmo sentido, Conrado Hubner Mendes: “As "onze ilhas” do STF continuam fortes como nunca. As decisões do Plenário, cada vez mais fragmentadas, parecem uma colcha de retalhos. E, na maior parte do tempo, o Supremo Tribunal Federal é um tribunal monocrático. Para mudar essa realidade, é preciso um choque de colegialidade". E, ainda: "Para Conrado Hübner Mendes, se a Corte deseja contribuir para a democracia, o STF deve levar a sério dois problemas. Deve definir critérios mais transparentes, racionais e menos arbitrários para a definição da pauta do Tribunal. E precisa disciplinar o poder de obstrução dos ministros, que individualmente podem sequestrar o Plenário por meio de pedidos de vista e de decisões liminares. Segundo o entrevistado, não compete ao STF ser vanguarda iluminista. O Tribunal, como Corte Constitucional, deve
} 
bastariam mudanças no regimento interno do tribunal, não sendo necessárias reformas constitucionais. (SILVA, 2009, p.219-220). Sua segunda ideia diz respeito à conciliação de proposições extremas, como as de Dworkin e Waldron, para superar as ideias de todo o poder nas mãos dos juízes ou dos legisladores, o que implica na construção de diálogos entre poderes, factível e necessária, especialmente no controle por omissão no que diz respeito a direitos sociais e políticas públicas. (SILVA, 2009, p. 219-220)

E como bem destaca Vanice Valle (2013), a consolidação do Estado Democrático de Direito "envolve o investimento na faceta participativa das escolhas públicas". Para além do amicus curiae e das audiências públicas, nessa seara se mostra importante o diálogo institucional, tangenciado pelo STF em algumas ocasiões, como, por exemplo, pelo Ministro Gilmar Mendes na audiência pública da saúde e no Mandado de Segurança 24.781 acerca do direito ao contraditório na análise de aposentadorias pelo TCU. Não obstante, nestes casos, o próprio STF foi quem convidou certos atores para o diálogo, ou seja, a reação - social ou institucional - sempre foi incorporada ao processo decisório nos termos da corte e não dos atores.

Isto é, não existe última palavra na democracia! E a interpretação da Constituição não é realizada apenas pela Corte Constitucional.

Nessa toada, é necessário buscar os ensinamentos de Peter Häberle, no sentido de que deve haver a participação dos cidadãos na interpretação e na construção constitucional, sendo importante o aspecto cultural. Isto é, para o autor, o ato de interpretar leva em conta a cultura, pois a narrativa seria um ato de constituição de sentido da norma e não extração de significado desta. Assim, tendo em vista o constitucionalismo democrático e a busca pela efetividade dos direitos fundamentais, o que se propõe é uma teoria de interpretação aberta da Constituição. Nesta linha, tanto menor for a densidade das normas constitucionais, maior deverá ser o caráter amplo e participativo dos intérpretes para fins de se estabelecer os seus conteúdos. Devendo, para tanto, a legislação ser elástica e ocorrer a criação de instrumentos de participação. Peter Häberle, em entrevista concedida à Cesar Landa, ressalta que o primeiro passo rumo à efetividade dos direitos fundamentais é o seu ensino nas escolas, no sentido de uma

enfrentar sensos comuns superficiais, lutar por preservar uma ambiciosa linguagem de direitos e desafiar os poderes eleitos a não subestimar os valores civilizatórios da Constituição."

Entrevista. Por Israel Nonato. 8.06.16. Conrado Hübner Mendes: "O STF é refém do capricho dos seus ministros". Por Israel Nonato. Disponivel em: http://www.osconstitucionalistas.com.br/conrado-hubner-mendeso-stf-e-refem-do-capricho-dos-seus-ministros.

Verificar: MENDES, 2008. 
“interpretação pedagógica da Constituição" 12 . (VALADÉS, 2009, p. 13). Nesse sentido, tendo em vista o constitucionalismo democrático e a busca pela efetividade dos direitos fundamentais, o que se propõe é uma teoria de interpretação aberta da Constituição, sendo que a cultura atinge a Constituição. A Constituição reflete a realidade e o fenômeno da mutação, nada mais é do que a decorrência do desenvolvimento da norma no tempo, sendo que a Constituição acaba sendo um trabalho de todos - "sociedade aberta de intérpretes da Constituição". (LEAL, 2008, p. 29)

É a democratização da tarefa interpretativa da Constituição, necessária no cenário brasileiro atual, que não deve ser atribuída apenas aos magistrados ou somente à um Poder ou uma instituição.

\section{Considerações Finais}

No decorrer do trabalho, verificou-se as principais implicações antidemocráticas do controle de constitucionalidade das leis pelo Judiciário, mormente diante de um forte controle como o brasileiro. Dessa forma, com base na obra de Roberto Gargarella, analisou-se os argumentos histórico, intertemporal e sobre a interpretação.

Concluiu-se que se há “crise" dos órgãos políticos, deve-se "aperfeiçoar os mecanismos majoritários" e não se desfazer deles, tendo em vista que o Judiciário também é afetado pelos problemas dos outros dois Poderes, sendo que as decisões dos juízes também podem ser motivadas por interesses próprios, assim como não se encontram livres de pressões externas, mormente em países nos quais o Poder Judiciário não é independente em relação aos órgãos políticos. Além disso, o contato dos juízes com os cidadãos no exercício da função é informal e ocasional. Tampouco o Judiciário garante a proteção das minorias, pois os juízes não representam a maioria numericamente falando, assim como não representam ou possuem uma conexão especial com a infinita diversidade de minorias que existem na sociedade.

E ainda não se pode dizer que o Judiciário age de modo mais racional e imparcial do que o Legislativo e o Executivo. Isso porque, como defende Roberto Gargarella, esta análise

\footnotetext{
${ }^{12}$ E sobre a ciência como cultura e participação dos cidadãos na interpretação e construção constitucional, afirma Peter Häberle na mesma entrevista:

“[...] Deve fazer compreender que, se bem que todos os cidadãos são 'guardiões da Constituição', justamente os tribunais constitucionais têm responsabilidade específica. Às vezes é necessário também julgar impopularmente, contra a opinião pública, que frequentemente na democracia de consenso é demasiado inconstante. A longo prazo um tribunal constitucional deve lograr a 'aceitação' de sua continuada jurisprudência, deve lograr ser compreensível para o cidadão e, acima de tudo, provar ser o tribunal dos cidadãos. Com isso traz uma contribuição (a sua) à forja da consciência constitucional e cumpre uma função da constituição. A globalização para além dos continentes já está garantida pela comunidade ibero-americana de cultura de direito. [...] Isso também seria uma contribuição para deixar atrás um falso eurocentrismo e para cultivar uma herança multicultural da humanidade (incluindo a herança indígena). A ciência do direito, entendida como ciência da cultura, faz parte dessa totalidade." - g. n. (VALADÉS, 2009, p. 15)
} 
está tomada de um "elitismo epistemológico". Inclusive, a ausência de um processo democrático de eleição dos juízes, pode implicar que estes elejam um modo de resolução de conflito que desconheça algum ponto de vista relevante. E é justamente na decisão de questões constitucionais básicas que se requer um amplo processo de discussão, inclusive com a sociedade. Portanto, não há que se falar em "última palavra” do Judiciário sobre a interpretação da Constituição em uma democracia.

E no tocante à tomada de decisão do Judiciário e ao controle de constitucionalidade, ressaltou-se a existência de duas espécies de deliberação: a interna e a externa. A primeira envolve a troca de razões e argumentos dentro de um grupo para que ele chegue a uma decisão (entre os juízes), já a deliberação externa envolve o esforço para convencer atores externos aos grupos (diálogo entre juízes e o mundo externo), sendo que uma democracia precisa de ambos os tipos de deliberação. E a realização desse diálogo externo exige a análise de formas alternativas de controle judicial de constitucionalidade, portanto.

Assim, toma-se o modelo canadense como um importante exemplo para que se tenha maior diálogo também no Brasil - que possui um forte controle de constitucionalidade. $\mathrm{O}$ Canadá possui tradição jurídica e política ligada à Inglaterra, e, assim, convivia com o princípio da supremacia do parlamento. Contudo, por ocasião das discussões para a implementação de sua Carta de Direitos (1982), acabou optando por fazer a previsão de um tipo de controle judicial de constitucionalidade que institucionaliza o diálogo institucional. Sendo que as notas características da ordem jurídica daquele país: sistema do Common Law, somado a uma tradição de soberania do parlamento de molde inglês, com recente introdução do judicial review, mitigado, porém, por uma cláusula que permite ao Parlamento a manutenção de legislação em vigor, ainda que contra decisão judicial expressa em sentido contrário (cláusula notwithstanding). (VICTOR, 2015, p.187).

Esse novo sistema de controle judicial de constitucionalidade, sobretudo em virtude da adoção da chamada cláusula notwithstanding, foi considerado como caracterizador de um modelo dialógico de judicial review, em razão de a referida cláusula permitir essa resposta legislativa à decisão da Suprema Corte. Isto é, esse sistema cria um diálogo institucional sobre o sentido da Constituição, ajudando a dissolver a dificuldade contramajoritária apontada no primeiro tópico. Assim, diante dessas objeções ao papel da Cortes, em especial da Suprema Corte como detentora da última palavra sobre o significado da Constituição, surge, com naturalidade, a ideia de diálogo institucional. 
Desse modo, entende-se que os diálogos do modelo canadense possibilitam um processo democrático, com a influência da Suprema Corte nas questões relevantes para o país, mas não a simples anulação de leis infraconstitucionais por ela. Assim, o diálogo entre a Suprema Corte e o Legislativo, marcado pelas respostas legislativas às decisões da Corte, caracteriza uma forma mais fraca de judicial review do Canadá em relação aos Estados Unidos e, sob o ponto de vista normativo, significa a minimização do discurso de ilegitimidade democrática do ativismo judicial em torno da Charter. Isto é, em um primeiro momento, pode-se ter decisões ativistas, mas em um segundo, tem-se respostas legislativas a essas decisões de forma que o processo legislativo resulte de uma dinâmica institucional bilateral, dialógica e não unilateral.

Portanto, conclui-se que o sistema canadense de diálogos pode servir de inspiração ao sistema brasileiro, no qual apenas o Judiciário tem proferido a "última palavra" sobre a interpretação da Constituição, mormente na tomada de decisões relevantes e que dizem respeito às questões políticas. Isso porque, ter a "última palavra" é custoso, pois lança para um único órgão, a defesa institucional final de todo um processo democrático, ou seja, de todo um diálogo que quer se manter aberto, tendo em vista que a democracia e o constitucionalismo são paradoxos necessários e que se aperfeiçoam constantemente. Assim, o sistema dialógico atende uma opção mais democrática e legítima para a realização da Constituição do que sistema da "última palavra".

\section{REFERÊNCIAS}

BARBOSA, Claudia Maria. A legitimidade do exercício da jurisdição constitucional no contexto da judicialização da política. In: BARRETTO, Vicente de Paulo; DUARTE, Francisco Carlos, SCHWARTZ (org.). Direito da sociedade policontextual. $1^{\text {a }}$ ed. Curitiba: Appris, 2013, v. 1.

Os novos oráculos da lei: a experiência do modelo misto canadense e a proposta da súmula de efeito vinculante no Brasil. Florianópolis, 2002, 226 f. Tese (Doutorado em Direito). Curso de Pós-graduação em Direito da UFSC.

BENVINDO, Juliano Zaiden. A última palavra, o poder e a história: o supremo tribunal federal e o discurso da supremacia no constitucionalismo brasileiro. Texto fornecido pelo autor.

CAMERON, Alex M. Power Without Law. The Supreme Court of Canada, the Marshall decisions, and the Failure of Judical activism. Montreal: McGill-Queen's, 2009.

CAMPOS, Carlos Alexandre de Azevedo. Dimensões do ativismo judicial do STF. São Paulo: Forense, 2014. 
GARGARELLA, Roberto. La dificuldade de defender el control judicial de las leyes. In Isonomía, vol. 6, Abr, 1997.

HÁBERLE, Peter. Hermenêutica constitucional: a sociedade aberta dos intérpretes da constituição: contribuiçãoo para a interpretaçãoo pluralista e 'procedimental"da constituiçãoo. Trad. Gilmar Ferreira Mendes. Sergio Antonio Fabris, Editor. Reimp. Porto Alegre, 2002.

HIRSCHL, RAN. Towards juristocracy. The origins and consequences of the new constitutionalism. First Harvard University Press, 2007.

HOGG, Peter H.; BUSHELL, Allison. The Charter Dialogue Between Court and Legislatures. Osgoode Hall Law Journal. Vol. 35 (1), 1997.

KOERNER, Andrei. Ativismo judicial: jurisprudência constitucional e política no STF pós-88. Novos estudos, v. 96, jul. 2013. p. 69-85

LEAL, Mônia Clarissa Henning. Jurisdição Constitucional Aberta: a Abertura Constitucional Como Pressuposto de Intervenção do Amicus Curiae no Direito Brasileiro. DPU, n. 21, maio/jun., 2008.

LEISHMAN, Rony. Against judicial activism. The decline of freedom and Democracy in Canada Montreal. McGill-Queen's, 2009.

MENDES, Conrado Hübner. Direitos Fundamentais, Separação de Poderes e. Deliberação. São Paulo, 2008, 224 f. Tese (Doutorado em Ciência Política). Curso de Pós-graduação da Faculdade de Filosofia, Letras e Ciências Humanas da USP.

ROACH, Kent. The Supreme Court on Trial. Judicial activism ou democratic dialogue.

SILVA, Virgílio Afonso da. O STF e o controle de constitucionalidade: deliberação, diálogo e razão pública. Revista de Direito Administrativo, v. 250, 2009.

STITT, Allan J. Mediating commercial disputes. Ontario: Canada Law Book, 2003.

VALADÉS, Diego. Conversas acadêmicas com Peter Häberle. São Paulo: Saraiva, 2009.

VALLE, Vanice R. L. do. Backlash à decisão do STF: pela naturalização do dissensso como possibilidade democrática. Texto decorrente da palestra proferida no II Seminário Internacional de Teoria das Instituições. 2013. Disponível em < https://www.academia.edu/5159210/Backlash_\%C3\%A0_decis\%C3\%A3o_do_Supremo_Tri bunal_Federal_pela_naturaliza\%C3\%A7\%C3\%A3o_do_dissenso_como_possibilidade_demo cr\%C3\%A1tica>. Acesso em 25 de outubro de 2016.

VICTOR, Sérgio Antônio Ferreira. Diálogo institucional e controle de constitucionalidade: Debate entre o STF e o Congresso Nacional. São Paulo: Saraiva, 2015.

WALDRON, Jeremy. The core of the case against judicial review. Yale Law Journal, v. $115,2006$. 